\title{
Editorial: Emerging Innovations in Counselling and Psychotherapy
}

\author{
Gary Nixon • Masood Zangeneh
}

Published online: 15 May 2012

(C) Springer Science+Business Media, LLC 2012

It is with great excitement that we bring to you a special issue on leading and emerging counselling and psychotherapy innovations in addictions and mental health. The intention was to deliberately give this issue a transformational intensity in that it was a special goal that the articles speak of the phenomenon of vital interest in that people would find the stories of clinical transformation ground breaking and pull the readers in themselves. In short, we were hoping the articles would not only be well written, scholarly, and use evidence based interventions, but also be compelling. Ideally, each reader will find two or three articles in this issue inspirational for their own transformational journey. We proceeded on four related but different theme pathways with this issue.

1) Integrating meditation and altered states of consciousness into psychotherapy

Michael DelMonte's Mindfulness meditation and Awareness: Constructivist, Psychodynamic and Eastern Perspectives picks up on this thread of awareness in looking at how mindfulness meditation and the contemplative wisdom tradition can be combined with psychodynamic and constructivist approaches to facilitate the therapeutic process and the transformational journey of the client. In a similar vein of working with altered states of consciousness, Marcia Rich's article Integrating Shamanic Methodology into the Spirituality of Addictions Recovery Work demonstrates how going beyond conventional psychotherapy strategies to embrace shamanic approaches in working with altered states of consciousness can open up new territory in working with clients. The shamanic tradition has been around for thousands of years but only recently has been incorporated into psychotherapy.

2) Nondual psychotherapy

\footnotetext{
G. Nixon

Faculty of Health Sciences, M 3043, University of Lethbridge, 4401 University Drive, Lethbridge, AB T1K 3M4, Canada

M. Zangeneh $(\square)$

International Journal of Mental Health and Addiction, Editorial Office: 54 Royal Chapin Crescent, Richmond Hill, Ontario, Canada

e-mail: masood.zangeneh@gmail.com
} 
Two articles in the emerging area of nondual therapy look at how the non-dual awakening tradition coming out of Advaita (not-two), Zen, Vedanta, Sufism and other wisdom traditions can be applied in a psychotherapy setting. Nondual psychotherapy focuses on the letting go of the judgments, complaints, stories and identity of the separate egoic self whether this is in grief work with Brian Theriault's Radical acceptance: A nondual psychology approach to grief and loss or in working with the narcissism behind sex addiction with Gary Nixon and Brian Theriualt's Nondual psychotherapy and second stage sexual addictions recovery: Transforming "Master of the Universe" narcissism into nondual being.

3) An integral transpersonal approach

Ken Wilber $(2000,2006)$ a pioneering transpersonal psychologist has recently developed an all quadrants all levels integral approach. Michael Fisher and Tess Davis utilize the latest theory of the integral approach in working with co-dependency issues in The Case of the Drunken Holon: An Integral Performative Co-Inquiry. Furthermore, Gary Nixon demonstrates how Wilber's clinical insights on the spectrum of development can be utilized to facilitate three stages of addictions recovery in, Transforming the addicted person's counterfeit quest for wholeness through three stages of recovery: A Wilber transpersonal spectrum of development clinical perspective.

4) Re-invigorating existential and hope strategies

As well, new innovations can be found by re-enlivening existing therapies in new ways. Geoff Thompson shows how the will to meaning aspect of the existential therapy tradition can be used as a centrepiece in addictions treatment in A Meaning-Centered Therapy for Addictions. Similarly, Corinne Koehn, Linda O'Neill, and John Sherry bring hope back to the forefront of working with youth in Hope-Focused Interventions in Substance Abuse Counselling.

We conclude this issue by presenting Brewerton and colleagues' examination of Holotropic Breathwork, a healing approach that incorporates teachings from modern consciousness research, anthropology, depth psychologies, transpersonal psychology, Eastern spiritual practices, and mystical traditions.

It is our hope that this special edition in new innovations is successful in opening up new fertile grounds of transformation for the readers both in our personal lives and our clinical work.

\section{References}

Wilber, K. (2000). Integral psychology: Consciousness, spirit, psychology, therapy. Boston: Shambhala. Wilber, K. (2006). Integral spirituality: A startling new role for religion in the modern and postmodern world. Boston: Shambhala. 